\title{
Atmospheric correction for sea surface temperature retrieval from single thermal channel radiometer data onboard Kalpana satellite
}

\author{
Naveen R Shahi ${ }^{1, *}$, Neeraj Agarwal ${ }^{2}$, Aloke K Mathur ${ }^{1}$ and Abhijit Sarkar ${ }^{1}$ \\ ${ }^{1}$ Atmospheric and Oceanic Sciences Group, Space Applications, Centre (ISRO), Ahmedabad 380 015, India. \\ ${ }^{2}$ Max Planck Institute, Hamburg, Germany. \\ *e-mail: navenshahi@gmail.com
}

\begin{abstract}
An atmospheric correction method has been applied on sea surface temperature (SST) retrieval algorithm using Very High Resolution Radiometer (VHRR) single window channel radiance data onboard Kalpana satellite (K-SAT). The technique makes use of concurrent water vapour fields available from Microwave Imager onboard Tropical Rainfall Measuring Mission (TRMM/TMI) satellite. Total water vapour content and satellite zenith angle dependent SST retrieval algorithm has been developed using Radiative Transfer Model [MODTRAN ver3.0] simulations for Kalpana 10.5-12.5 $\mu \mathrm{m}$ thermal window channel. Retrieval of Kalpana SST (K-SST) has been carried out for every half-hourly acquisition of Kalpana data for the year 2008 to cover whole annual cycle of SST over Indian Ocean (IO). Validation of the retrieved corrected SST has been carried out using near-simultaneous observations of ship and buoys datasets covering Arabian Sea, Bay of Bengal and IO regions. A significant improvement in Root Mean Square Deviation (RMSD) of K-SST with respect to buoy $(1.50-1.02 \mathrm{~K})$ and to ship datasets $(1.41-1.19 \mathrm{~K})$ is seen with the use of near real-time water vapour fields of TMI. Furthermore, comparison of the retrieved SST has also been carried out using near simultaneous observations of TRMM/TMI SST over IO regions. The analysis shows that K-SST has overall cold bias of $1.17 \mathrm{~K}$ and an RMSD of $1.09 \mathrm{~K}$ after bias correction.
\end{abstract}

\section{Introduction}

A satellite-borne infrared radiometer observing the ocean surface is sensitive to radiance which may emanate from both the ocean surface and the intervening atmosphere. Therefore the satellite measurements of SST are made using regions of the electromagnetic spectrum where the sea surface emissivity is nearly unity $(>0.95)$ and the atmosphere is relatively transparent, i.e., 50$90 \%$ transmission of surface emission to the top of atmosphere. Retrieval of SST from thermal infrared window channels $(10.5-12.5 \mu \mathrm{m})$ over cloud-free oceanic regions requires atmospheric corrections arising due to attenuation of signal by intervening atmospheric water vapour. This correction is more in tropics during summers due to higher amount of atmospheric moisture (Anding and Kauth 1970; Prabhakar et al 1974; Barton 1983; Shenoi 1999; Mathur et al 2002). The interpretation and validation of satellite measurements of SST from both polar-orbiting and geostationary satellites is affected by the presence of the oceanic skin layer (see, e.g., Katsaros 1980;

Keywords. Retrieval; sea surface temperature; Kalpana satellite; TRMM/TMI; water vapour fields. 
Robinson et al 1984; Schluessel et al 1990) and diurnal thermocline. While infrared radiometers at 10-12 $\mu \mathrm{m}$ measure the temperature of the ocean at depths of the order of a few microns, the buoy measurements commonly used to develop and validate the satellite algorithms are made at depths of the order of nearly $1 \mathrm{~m}$. Models and measurements of the near-surface temperature profile have demonstrated the potential for significant variability in the temperature difference between these depths, especially during daytime with low winds and strong solar heating (Fairall et al 1996; Soloviev and Schluessel 1996; Webster et al 1996; Donlon et al 1999). Because of the interest in upper ocean heat content and for consistency with historical SST measurements, the 'bulk' temperature beneath the skin layer is frequently the temperature of interest rather than the 'skin' temperature actually measured by the satellite. The field measurements indicate that there is a noticeable difference between the bulk and skin temperatures (skin effect), which vary over the diurnal cycle (Hook et al 2003).

Algorithms that attempt to estimate the bulk temperature by directly regressing the satellite brightness temperature measurements against in situ bulk temperature measurements are subject to errors resulting from variability in the difference between the skin and bulk temperatures. This introduces additional error when measuring SST from geostationary satellites such as K-SAT since measurements are collected regularly through periods when the difference can vary strongly. Although there is a water vapour channel (central wavelength $6.7 \mu \mathrm{m}$ ) onboard K-SAT, its weighting function peaks at around $500 \mathrm{mb}$ which renders it of little use for SST retrievals. This is due to the fact that Infra-Red (IR) signal is attenuated by total water vapour content in the atmosphere, and $90 \%$ of which resides within $1 \mathrm{~km}$ of the lower atmosphere. Furthermore, the water vapour content at $500 \mathrm{mb}$ is not correlated with total atmospheric water vapour content.

The purpose of this article is to set out what can (and cannot) be reasonably expected in the absence of a suitable channel for total water vapour estimation in single IR channel geostationary satellite like K-SAT. Water vapour dependent SST retrieval coefficients have been derived with the use of Radiative Transfer model (RTM) and knowledge of instrument spectral characteristics for atmospheric correction in the proposed algorithm for retrieving SST over IO. The atmospheric correction is being carried out by using total water vapour fields from TRMM/TMI $21 \mathrm{GHz}$ channel measurements. A comprehensive validation with in-situ measurements and comparison with TMI SST is carried out over various regions of IO.

\section{SST retrieval and simulation algorithm}

The proposed retrieval algorithm schemes are based on RTM, involving physical modelling for generating brightness temperatures at top of the atmosphere for the K-SAT thermal channel. The brightness temperatures thus simulated describe the spatial and temporal variability of tropical marine surface and atmospheric parameters. To simulate the brightness temperatures, Moderate Resolution Transmittance code (MODTRAN) (Berk et al 1989) is used. MODTRAN is a computer code developed by Spectral Sciences Inc. which is designed to determine atmospheric transmittance and radiance at moderate resolution $\left(1 \mathrm{~cm}^{-1}\right)$. It is based on AFGL's LOWTRAN-7 code (Kneizys et al 1989). TOVS Initial Guess Retrieval (TIGR) (Scott and Chedin 1981) dataset has been used to construct the tropical marine subset. These profiles have been extracted for the spatial domain based upon K-SAT field of view from $50^{\circ} \mathrm{S}-50^{\circ} \mathrm{N}$ and $30^{\circ}-120^{\circ} \mathrm{E}$. The simulations have been performed on each radio sounding of the TIGR 'tropical maritime' subset under the following conditions:

- TIGR profiles are available at 48 levels. They have been converted to the 34 level MODTRAN inputs by using directly the TIGR levels from the surface to $300 \mathrm{hPa}$ (15 levels), sampling every 4 levels above $300 \mathrm{hPa}$ (5 levels are excluded this way) and removing the upper 9 levels.

- In addition to the profiles of temperature and water vapour of TIGR, mixed gases profiles from MODTRAN standard atmospheres have been added according to the time and location of each radio sounding.

- No aerosols have been considered.

- Satellite zenith angles: Coefficients have been generated for seven zenith angles $0,24,36,42$, 48, 54 and 60 degrees.

- Surface temperatures: For each radio sounding three surface temperatures have been assigned: Ta 1000 (1000 mb air temperature), Ta $1000+1^{\circ} \mathrm{C}$, Ta $1000-1^{\circ} \mathrm{C}$.

- Radiances have been simulated for K-SAT thermal channel with emissivity values calculated from the tables of Masuda et al (1988) with a moderate wind speed of $5 \mathrm{~m} / \mathrm{s}$.

The simulations applied on the 'global maritime' subset of TIGR produced 5820 cases. Before being used to derive algorithm, the simulated radiative temperatures were filtered. To keep the simulated temperatures within realistic limits, the following thresholds were finally applied:

$$
T_{s}-T_{b t}>0.5 \mathrm{~K},
$$




$$
\begin{gathered}
-2 \mathrm{~K}<T_{S}<35 \mathrm{~K}, \\
W V>0.5 \mathrm{~g} \cdot \mathrm{m}^{-2},
\end{gathered}
$$

where $T_{s}$ is SST, $T_{b t}$ is the channel brightness temperature and $W$ is the total column water vapour content. Hereafter, radiances were integrated for each channel with the sensor filter functions and converted into radiative temperatures. These brightness temperatures were perturbed further by introducing the sensor noise. Typical plots of humidity $(H)$ and temperature $\left(T_{a}\right)$ profiles used in algorithm development are shown in figure 1. Based on radiative transfer simulations, water vapour and satellite zenith angle dependent SST retrieval coefficients have been developed (Mathur et al 2008). The general form of SST retrieval algorithm is:

$$
\mathrm{SST}=A(\theta)+B(\theta) T_{B}+C(\theta) W V
$$

where $T_{B}, W V, A(\theta), B(\theta), C(\theta)$ are respectively brightness temperature of the Kalpana IR imager channel (10.5-12.5 $\mu \mathrm{m})$, 3-day running mean of total water vapour content, satellite zenith angle

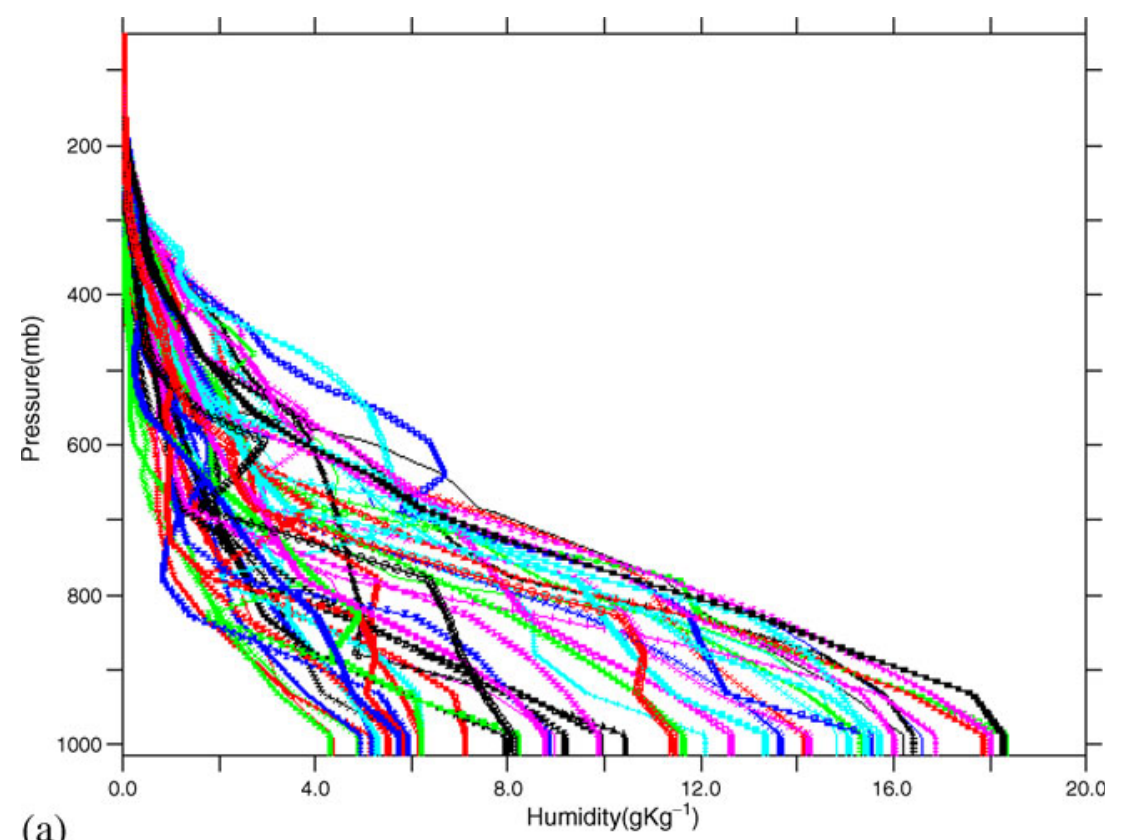

(a)

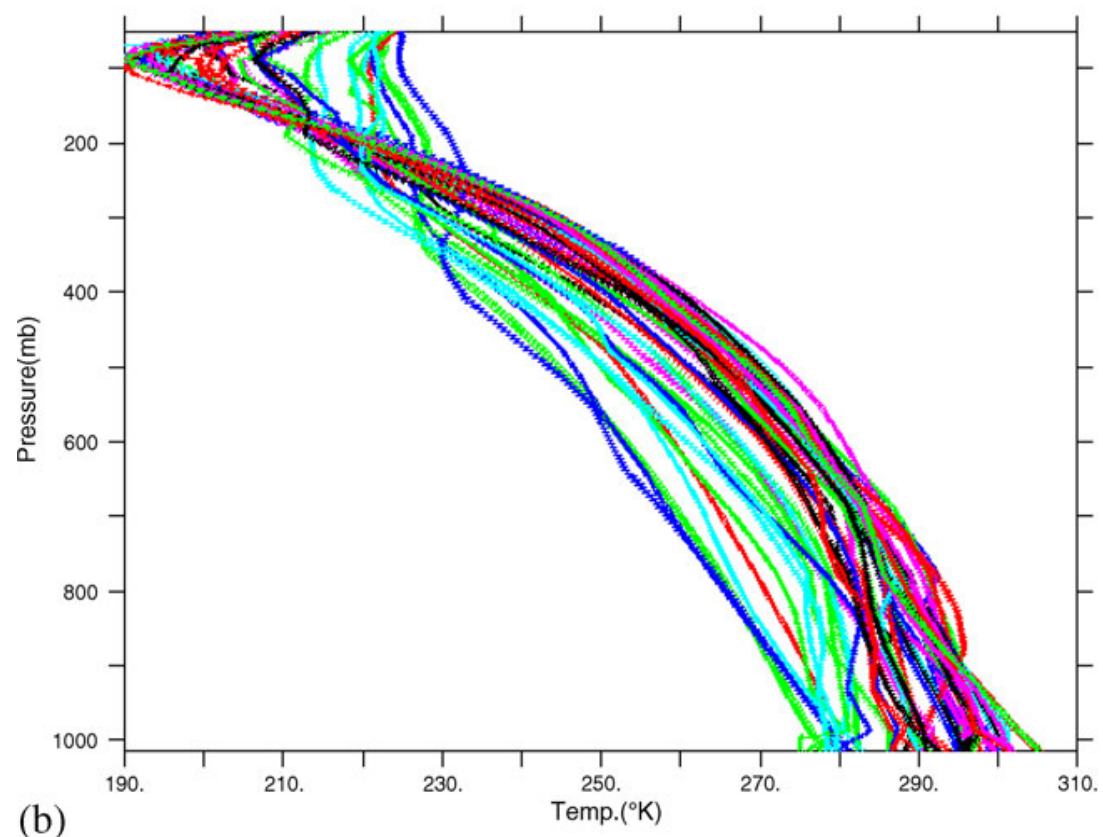

Figure 1. Variation of (a) specific humidity and (b) temperature profiles used in radiative transfer simulation. 
Table 1. Satellite zenith angle dependent regression coefficients generated through MODTRAN simulations.

\begin{tabular}{lccc}
\hline $\begin{array}{l}\text { Satellite } \\
\text { zenith angle }\end{array}$ & $\mathrm{A}(\theta)$ & $\mathrm{B}(\theta)$ & $\mathrm{C}(\theta)$ \\
\hline 0 & 7.3088 & 0.97000 & 1.3829 \\
24 & 10.951 & 0.95746 & 1.4858 \\
36 & 23.675 & 0.91434 & 1.6029 \\
42 & 29.173 & 0.89698 & 1.6403 \\
48 & 36.733 & 0.87125 & 1.7716 \\
\hline
\end{tabular}

( $\theta)$ dependent regression coefficients generated through radiative transfer simulations. The coefficients are given in table 1 but are considered for $\theta<45^{\circ}$ angle. This aims to account for possible nonlinearities as a function of $\sec (\theta)$.

Atmospheric correction ( $W V$ in equation 1 ) is done using TMI running 3-day average water vapour field data. The satellite zenith angle is computed for each pixel $(8 \times 8 \mathrm{~km})$ along the scan and then SST retrieval coefficients are interpolated between the two computed angles. Satellite observations are obtained for 1560 scan lines and 1676 pixels, falling beyond $45^{\circ}$ of zenith angle are not considered for SST retrieval. The increased path length at high satellite zenith angles $\theta$ results in greater attenuation of IR radiation by water vapour and other atmospheric constituents. The brightness temperatures observed at the edge of the scan are colder than those observed at the center of the scan, and the difference depends on the satellite angle $\theta$, the sensor's channel wavelength, and the water vapour column in the observed regions (Ricciardulli and Wentz 2004).

In the present algorithm, cloudy pixels are detected through threshold and spatial coherence techniques (Coakley and Bretherton 1982) in thermal band and the pixels are flagged based on the above criterion. Thresholding technique assumes that over oceans in Indian domain brightness temperature in thermal band is greatly affected by the presence of clouds, resulting in decreased brightness temperature from cold cloud tops. Spatial coherence method is based on the assumption that SST is homogeneous and warmer than clouds; thus clouds can be identified where the scene brightness temperature has lower mean value and larger standard deviation. SST is computed only over clear oceanic regions. The retrieved K-SST at every pixel is passed through a quality control check and if the absolute difference between the K-SST and the climatological SST (Reynolds 1988; Reynolds and Smith 1994), Reynolds (1988) is strictly below $3^{\circ} \mathrm{C}$ and retrieved SST is lower than three times of the

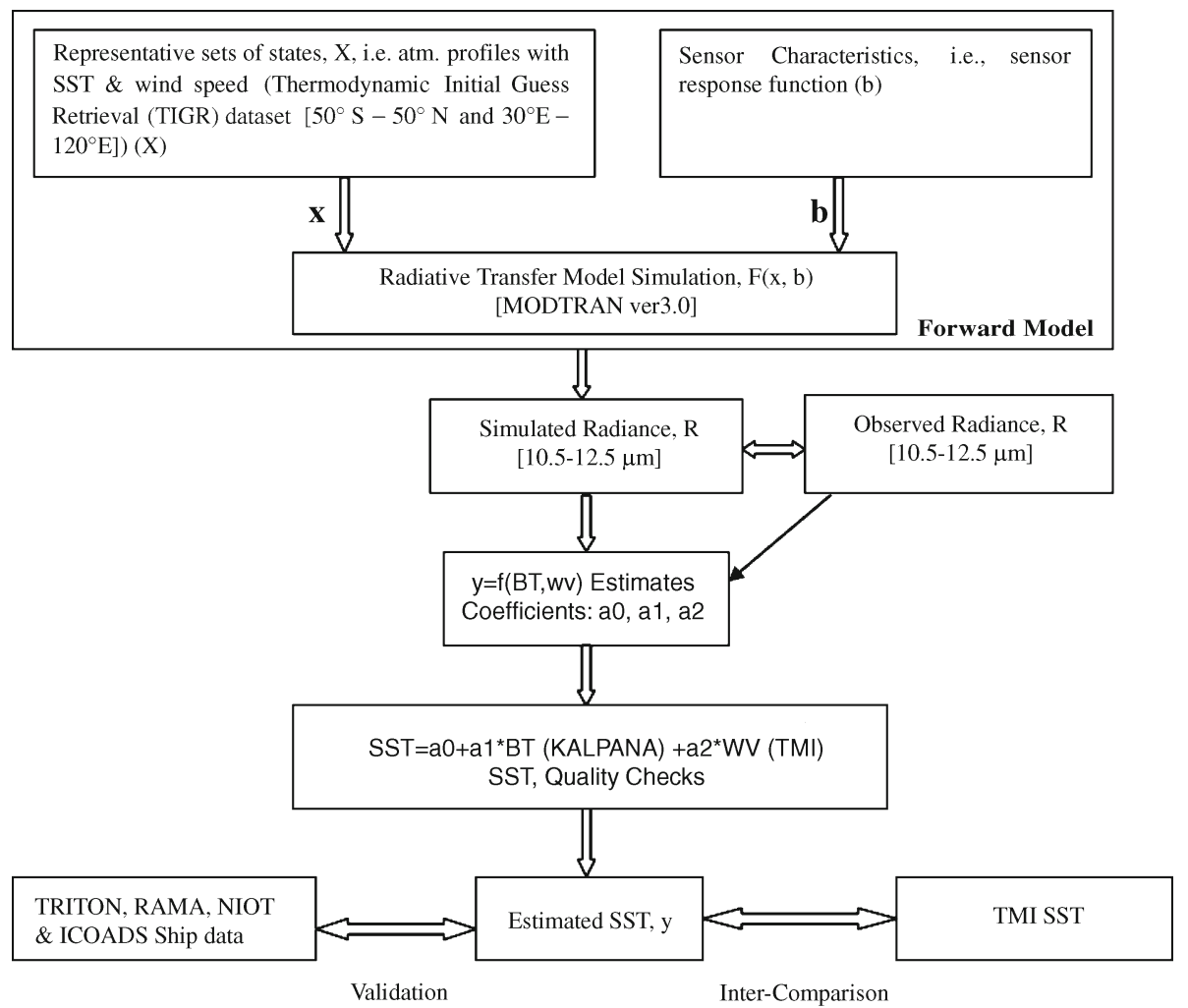

Figure 2. Flowchart representing schematic process of retrieval using radiative transfer model and validation/ Intercomparison of K-SST. 
Table 2. Characteristics of VHRR sensor onboard Kalpana satellite.

\begin{tabular}{lcc}
\hline & $\begin{array}{c}\text { Channel } \\
\text { wavelength } \\
\text { band }(\mu \mathrm{m})\end{array}$ & $\begin{array}{c}\text { Resolution } \\
(\mathrm{km})\end{array}$ \\
\hline VHRR & $0.55-0.75$ & 2 \\
& $10.5-12.5$ & 8 \\
& $5.7-7.1$ & 8 \\
\hline
\end{tabular}

standard deviation of climatological SST then only it is flagged as best quality.

\section{Data used}

Intercomparison and in-situ validation of K-SST as shown in schematic flowchart (figure 2), is carried out using near-simultaneous measurements from TRMM/TMI SST, International Comprehensive Oceans Atmosphere Dataset (ICOADS) ship, Triangle Trans-Ocean Buoy Network (TRITON), The Research Moored Array for African-AsianAustralian Monsoon Analysis and Prediction (RAMA), and National Institute of Ocean Technology (NIOT) buoys.

\subsection{Satellite data}

Geostationary K-SAT carrying VHRR and Data Relay Transponder (DRT) was launched to the orbit on September 12, 2002 and is positioned at $74^{\circ} \mathrm{E}$ longitude. Objectives of the meteorological payloads onboard are cyclone and monsoon monitoring, cloud motion vectors winds, rainfall estimation, floods/intense precipitation monitoring, snow-cover detection, mesoscale studies, etc. Details of VHRR are given in table 2. K-SAT thermal channel data for whole year of 2008 has been processed for every half-an-hourly acquisition to derive K-SST using the proposed algorithm for the IO domain and averaged spatially at $0.5 \times 0.5$ deg. TRMM/TMI SST is obtained from www.ssmi.com/tmi, derived using low-frequency channel $(10.7 \mathrm{GHz})$ radiances of microwave (MW) sensors (Wentz et al 2000) at a grid resolution of $0.25 \times 0.25 \mathrm{deg}$. TMI SSTs are routinely processed at Remote Sensing Systems (RSS). TMI ocean data are produced using a physically based algorithm developed from a radiative transfer model using simulated data. Reynolds SSTs are used to calibrate and remove biases from TMI brightness temperatures. Data within $100 \mathrm{~km}$ from land are excluded in the algorithm development, but the full range of wind observations is included. The algorithm for retrieving SSTs from MW observations is described by Wentz and Meissner (1999). TMI SSTs known to have a mean bias of $-0.07^{\circ} \mathrm{C}$ and a standard deviation of $0.57^{\circ} \mathrm{C}$ when compared to the TAO/TRITON and PIRATA SSTs (Gentemann et al 2004). Monthly climatology of NOAA water vapour climatology project (NVAP), water vapour fields at $1^{\circ} \times 1^{\circ}$ global bin (Randel

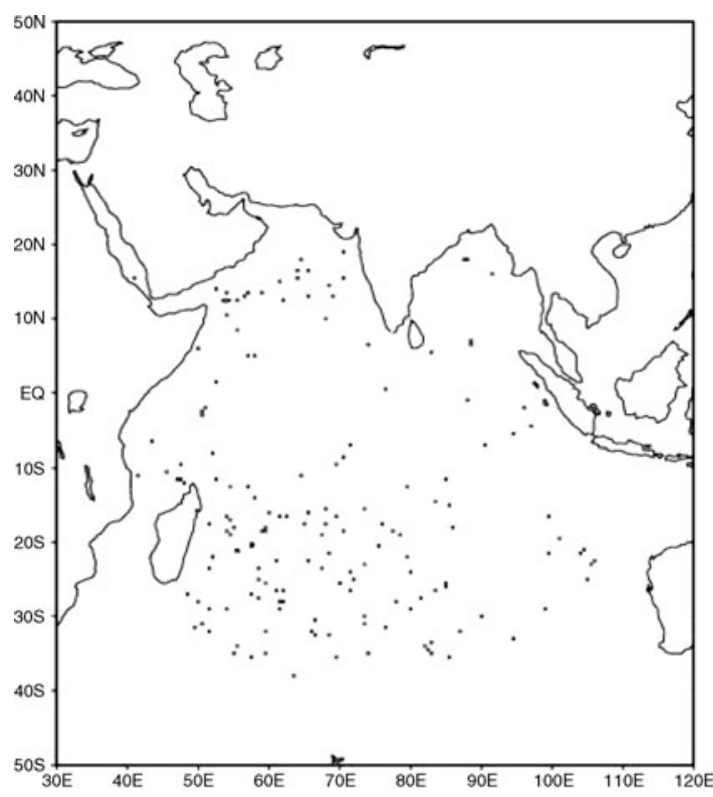

(a)

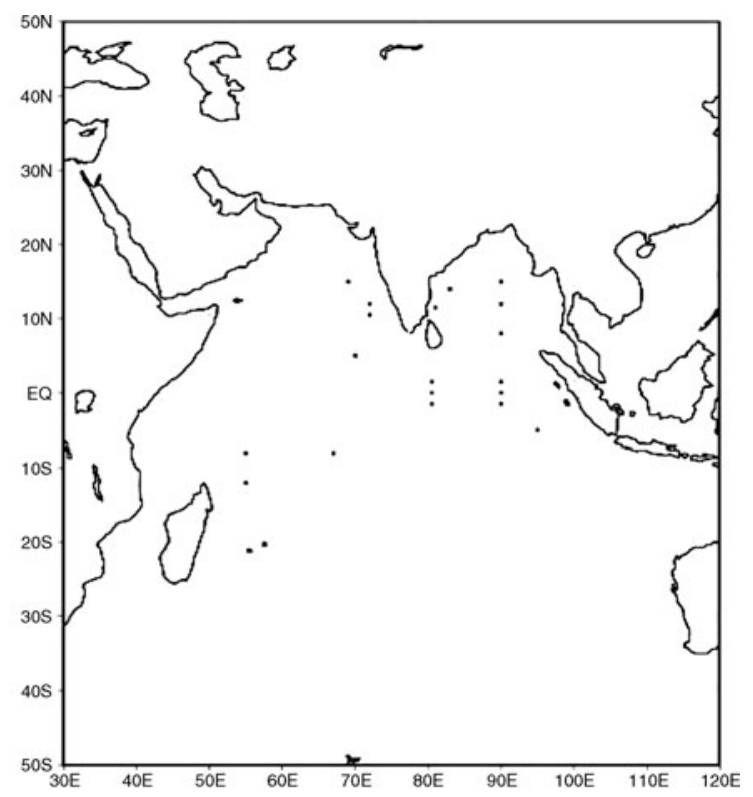

(b)

Figure 3. The Closed circles indicate location of (a) ICOADS-SHIP and (b) moored met-ocean buoys measurements in Indian Ocean during 2008. 
Table 3. Statistics of validation of K-SST with ICOADS ships and buoys observations.

\begin{tabular}{lcccc}
\hline Statistics & $\begin{array}{c}\text { ICOADS } \\
(\text { TMI-WV })\end{array}$ & $\begin{array}{c}\text { Buoy } \\
(\text { TMI-WV })\end{array}$ & $\begin{array}{c}\text { ICOADS } \\
(\text { NVAP-WV })\end{array}$ & $\begin{array}{c}\text { Buoy } \\
\text { (NVAP-WV) }\end{array}$ \\
\hline Number of points & 146 & 167 & 146 & 167 \\
Correlation with K-SST & 0.90 & 0.59 & 0.41 & 0.45 \\
Bias (K) & 1.94 & 1.06 & 1.85 & 1.87 \\
RMSD after bias & 1.19 & 1.02 & 1.41 & 1.50 \\
$\quad$ correction (K) & & & & \\
\hline
\end{tabular}

Table 4. Statistics of comparison of K-SST with TMI SST observations.

\begin{tabular}{lrccc}
\hline Month (2008) & No. of points & Bias (K) & RMSD (K) & $\begin{array}{c}\text { RMSD (K) } \\
\text { (after bias correction) }\end{array}$ \\
\hline January & 75 & -2.22 & 2.32 & 0.68 \\
February & 190 & -1.20 & 1.88 & 1.34 \\
March & 62 & -2.10 & 2.28 & 0.89 \\
April & 191 & -1.33 & 1.67 & 1.05 \\
May & 624 & -0.59 & 1.22 & 1.07 \\
June & 12 & -1.63 & 1.71 & 0.51 \\
July & 3 & -1.04 & 1.67 & 1.30 \\
August & 13 & -1.41 & 1.64 & 0.83 \\
September & 53 & -1.67 & 1.92 & 1.14 \\
October & 23 & -2.57 & 2.74 & 0.95 \\
November & 32 & -3.03 & 3.2 & 1.33 \\
December & 51 & -2.35 & 2.57 & 1.22 \\
Annual & 1329 & -1.17 & 1.73 & 1.09 \\
\hline
\end{tabular}

et al 1996) and TRMM/TMI 3-day average water vapour fields using $21 \mathrm{GHz}$ channel are used in the SST algorithm for the impact analysis.

\subsection{Buoy data}

Equipped with oceanographic and meteorological sensors, ICOADS global marine SST observations (taken at $3 \mathrm{~m}$ below the sea surface) have been obtained from ftp://ftp.emc.ncep.gov/gts/obs. SST measurements of TRITON buoys (located at $1.5^{\circ} \mathrm{S}$, $90^{\circ} \mathrm{E}$ and $5^{\circ} \mathrm{S}, 95^{\circ} \mathrm{E}$ ) of eastern equatorial region, a detailed description of the sensor specifications and data sampling intervals are described in McPhaden et al (1998) and Kuroda (2002); these data are available at http:/www.jamstec.go.jp/ jamstec/TRITON/. RAMA (McPhaden et al 2009) buoy array in Bay of Bengal and equatorial IO are available at http://www.pmel.noaa.gov/tao/ oceansites/index.html. NIOT buoys are deployed over different locations of Arabian Sea, Bay of Bengal and IO and SST datasets are available at www.incois.res.in. SST measured just about $1.5 \mathrm{~m}$ below the surface by moored buoys has been taken for validation. Figure $3(\mathrm{a}$ and $\mathrm{b})$ shows the locations of the ICOADS ships and moored buoys, respectively.

\section{Validation results}

\subsection{Validation with in-situ SST}

In order to ensure appropriate validation of the retrieved K-SST utilizing TMI-water vapour fields over the spatial domain between $50^{\circ} \mathrm{S}-50^{\circ} \mathrm{N}$ and $30^{\circ}-120^{\circ} \mathrm{E}$, and with every half hourly scan, ICOADS-SST observations are also put in the same grid resolution as that of K-SST, i.e., $0.5^{\circ} \times 0.5^{\circ}$. In the case of validation with moored-buoy observations the collocation with $\mathrm{K}$-SST is performed within $\pm 0.5^{\circ}$ and 6 hours because of uneven and sparse datasets of in-situ SST. Validation of nearsimultaneous K-SST with ICOADS ship observations yields $1.19 \mathrm{~K}$ RMSD after bias correction. TRITON, RAMA and NIOT buoys observations yield $1.02 \mathrm{~K}$ RMSD after bias correction. Sensitivity of water vapour fields of NVAP and TMI for the collocated datasets with above-mentioned conditions is seen in table 3 showing inadequacy of atmospheric correction provided by the monthly climatology of water vapour fields.

\subsection{Inter-comparison with satellite SST}

Intercomparison of K-SST is carried out using nearsimultaneous measurements from TRMM/TMI. 

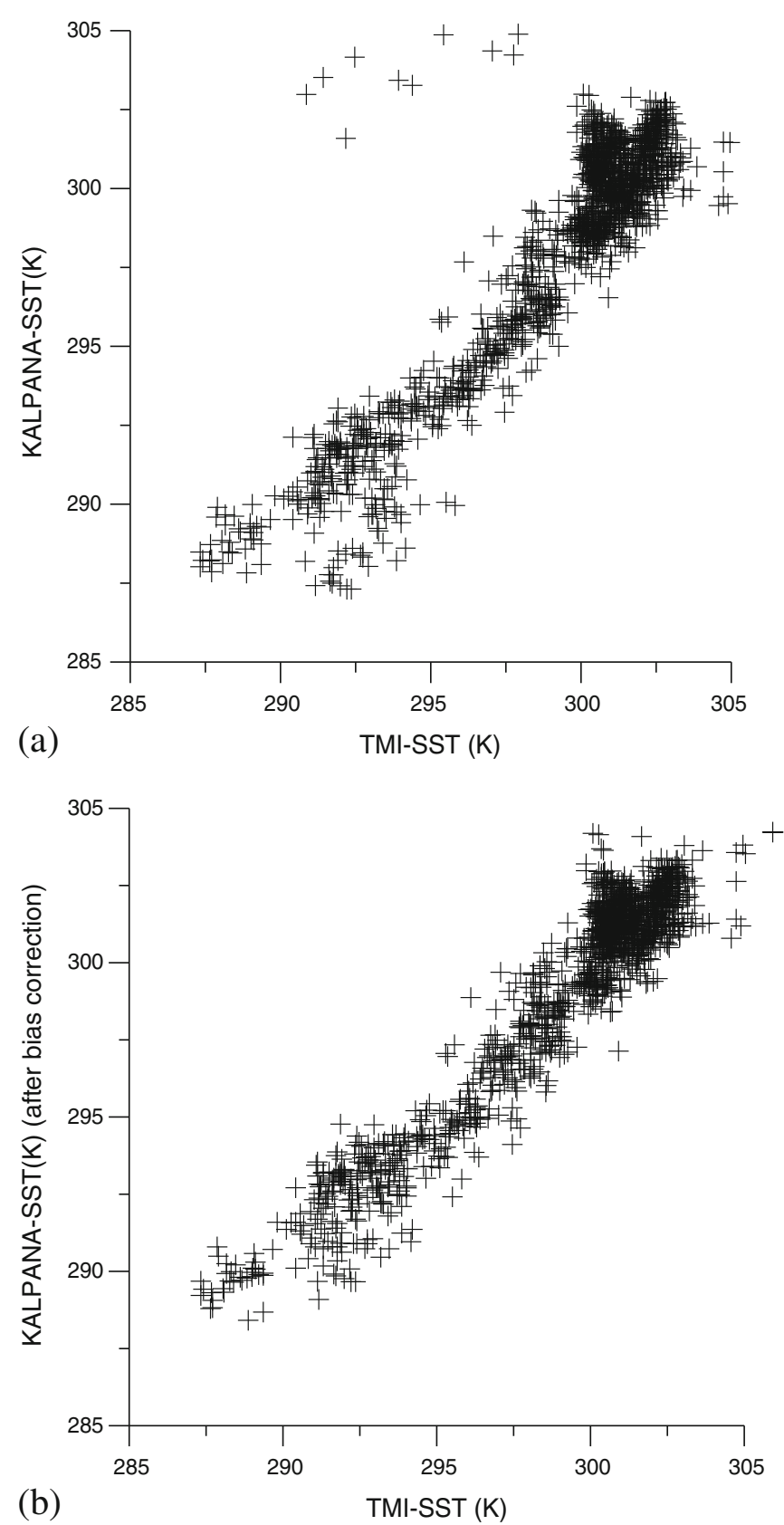

Figure 4. Shows scatter plot of near simultaneous observations of TMI (a) before and (b) after bias correction with respect to K-SST for 2008.

In order to ensure appropriate comparison of K-SST obtained using TMI-water vapour fields over the study domain, TMI-SST observations are also put in the same grid resolution as that of K-SST, i.e., $0.5^{\circ} \times 0.5^{\circ}$. Collocation of TMI-SST and K-SST observations is performed within $\pm 0.5^{\circ}$ spatial and one hour temporal resolution. Measurements where the difference between K-SST and TRMM SST is more than $5 \mathrm{~K}$ are filtered with the assumption that grid contains partial cloudy pixels. Monthly bias and root mean square deviation has been computed for all the collocated $\mathrm{K}$ and TRMM SST observations and are shown in table 4 .

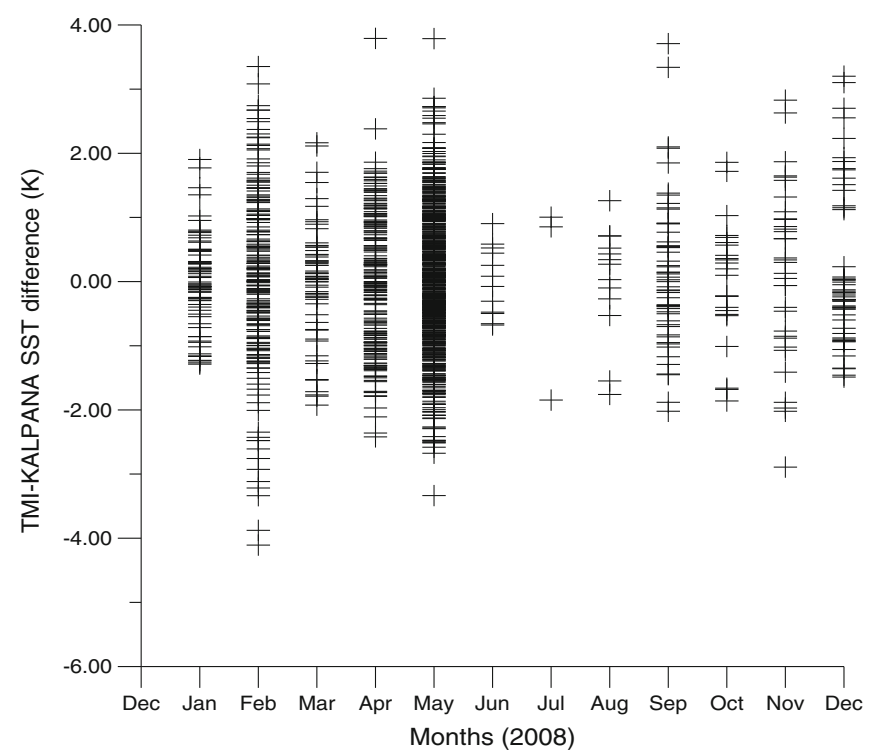

Figure 5. TMI and Kalpana collocated SST difference for the whole annual cycle (2008).

It is evident from table 4 that $\mathrm{K}$-SST is underestimating in all the months. In the winter months (October-March), the RMSD is higher than the summer months (April-September). But after bias correction, RMSD decreases to nearly $1 \mathrm{~K}$ (figure 4) and RMSD is independent of season. Comparison of near-simultaneous K-SST with TMI-SST observations yields $1.09 \mathrm{~K}$ root mean square deviation after bias correction (table 3). TMI and K-SAT collocated SST differences have been plotted for 2008 in figure 5.

\section{Conclusions}

Accuracy problems can result from measuring SST from geostationary satellites. These include the possibility of extreme satellite viewing angles, variable heating and solar illumination of the satellite sensor, and non-uniform sampling of all possible surface conditions. However, sensor calibration plays a crucial role in the determination of overall accuracy of K-SST and oceanic nearsurface temperature profile effects have a significant impact on the accuracy and interpretation of the measurements. The better accuracies (figure 6) obtained with the buoy data may be attributed to the fact that these measurements are made just below the sea surface and hence closer to satellite SST while ships measurements being made at $3 \mathrm{~m}$ below the sea surface are relatively warmer than actual sea surface. Sensitivity of water vapour fields is seen in K-SST using TMI 3-day average water vapour and NVAP monthly water vapour climatology in SST algorithm and are presented in 


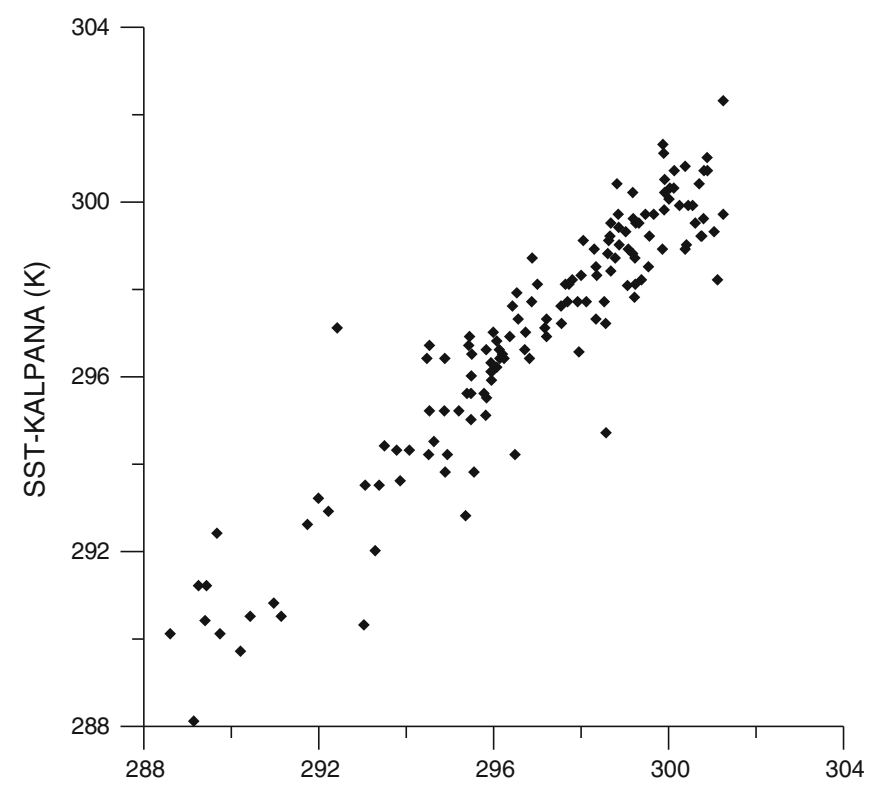

(a)

SST- ICOADS (K)

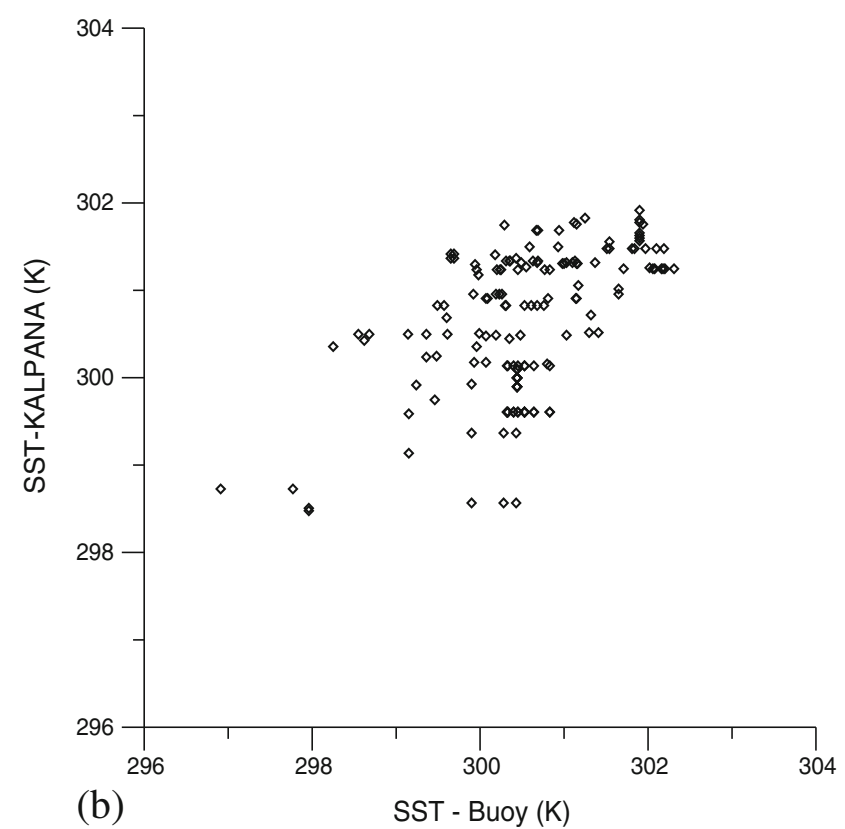

Figure 6. Shows scatter plot of near simultaneous observations of (a) ICOADS and (b) buoy with respect to K-SST.

table 3 for the collocated datasets. Low correlation values and high RMSD even after bias correction is obtained in cases of monthly climatology of water vapour fields, which shows the necessity of using near real-time water vapour fields in SST retrievals with single channel IR radiometer data over tropics. Further the data analysis shows improvement in K-SST after applying water vapour correction through TMI data and validated with in situ measurements. As seen in table 3, the RMSD with respect to ship and buoy improved from $1.14-1.19 \mathrm{~K}$ and $1.50-1.02 \mathrm{~K}$, respectively indicating the importance of more realistic water vapour data from TMI in K-SST retrieval.

Considering the fact that SST retrieval is being carried out using single thermal channel and TRMM/TMI WV observations are 3-day average, the accuracy achieved on an instantaneous basis is encouraging. The residual differences might be due to undetected clouds or aerosols in infrared retrievals, as well as errors due to the regression coefficients for both day time and night time retrieval provided at different scan angles obtained from linear regression of 10.5-12.5 $\mu \mathrm{m}$ channel brightness temperature against the buoy data which is usually bulk temperature but the infrared sensors observe the ocean skin temperature at a depth of few microns, while microwaves measure the subskin temperatures at a depth (Wentz et al 2000). In single channel SST retrieval, use of simultaneous satellite measured water vapour field will lead to further improvement in SST accuracy. The method provides a simple way to study the spatial thermal gradient and long term SST trends with single channel radiometer onboard geostationary satellites like Kalpana and propose to extend this study by comparing with other single channel algorithm (e.g., Zhou et al 2010).

\section{Acknowledgments}

Authors would like to thank Dr R R Navalgund, Director, Space Applications Centre, Dr J S Parihar, Deputy Director, Earth and Planetary Sciences Area and, Dr P K Pal, Group Director, Atmospheric and Oceanic Sciences Group for their constant encouragement. TAO Project Office of NOAA/PMEL is gratefully acknowledged for TRITON/RAMA data. NIOT, MOSDAC and ICOADS are gratefully acknowledged for SST data. TMI data are produced by Remote Sensing Systems. Also acknowledge Dr B S Gohil, Head, Geo-physical Parameter Retrievals Division. The authors thank the anonymous reviewers for their suggestions to improve the manuscript.

\section{References}

Anding D and Kauth R 1970 Estimation of sea surface temperature from space; Remote Sens. Environ. 1 217-220.

Barton I J 1983 Dual channel satellite measurements of sea surface temperature; Quart. J. Roy. Meteor. Soc. 109 365-378.

Berk A, Bernstein L S and Robertson D C 1989 MODTRAN: A Moderate Resolution Model for LOWTRAN 7; GL-TR89-0122.

Coakley J A and Bretherton F P 1982 Cloud cover from high resolution scanner data: Detecting and allowing for partially clouded fields of view; J. Geophys. Res. 87 4917-4932. 
Donlon C J, Nightingale T J, Sheasby T, Turner J, Robinson I S and Emery W J 1999 Implications of the oceanic thermal skin temperature deviation at high wind speed; Geophys. Res. Lett. 26 2505-2508.

Fairall C W, Bradley E F, Godfrey J S, Wick G A, Edson J B and Young G S 1996 Cool skin and warm layer effects on sea surface temperature; J. Geophys. Res. 101 1295-1308.

Gentemann C L, Wentz F J, Mears C A and Smith D K 2004 In situ validation of Tropical Rainfall Measuring Mission microwave sea surface temperatures; J. Geophys. Res. 109, C04021, doi: 10.1029/2003JC002092.

Hook S J, Prata F J, Alley R E, Abtahi A, Richards R C, Schladow S G and Palmarsson S O 2003 Retrieval of lake bulk and skin temperatures using along-track scanning radiometer (ATSR-2) data: A case study using Lake Tahoe, California; J. Atmos. Ocean. Tech. 20 534-548.

Katsaros K B 1980 The aqueous thermal boundary layer; Bound.-Layer Meteor. 18 107-127.

Kneizys F, Shettle E P, Anderson G P, Abreu L W, Chetwind J H, Selby J E A, Clough S A and Gallery W O 1989 Atmospheric transmittance/radiance computer code-LOWTRAN-7, Airforce Geophysical Laboratory, Massachusetts, USA, 01731.

Kuroda Y 2002 TRITON: Present status and future plan, TOCS Rep. 5, 77 pp., Jpn. Agency for Mar.-Earth Sci. and Technol., Kanagawa, Japan (available at http://www. jamstec.go.jp/jamstec/TRITON/future/index.html).

Masuda K, Takashima T and Takayama Y 1988 Emissivity of pure and sea waters for the model sea surface in the infrared window region; Remote Sens. Environ. 24 313-329.

Mathur A K, Agarwal V K and T C Panda 2002 Validation of ERS-1/ATSR derived SST in Indian waters; Int. J. Remote Sens. 23(24) 5155-5163.

Mathur A K, Agarwal N, Shahi N R and Sarkar A 2008 Impact of water vapor fields on sea surface temperature retrievals from KALPANA data, Proceedings: 15th National Space Science Symposium (NSSS-2008), Radio Astronomy Centre, NCRA-TIFR.

McPhaden M J, Busalacchi A J, Cheney R, Donguy J R, Gage K S, Halpern D, Ji M, Julian P, Meyers G, Mitchum G T, Niiler P P, Picaut J, Reynolds R W, Smith N and Takeuchi K 1998 The tropical ocean-global atmosphere (TOGA) observing system: A decade of progress; J. Geophys. Res. 103 14,169-14,240.

McPhaden M J, Meyers G, Ando K, Masumoto Y, Murty V S N, Ravichandran M, Syamsudin F, Vialard J, Yu L and Yu W 2009 RAMA: The research moored array for African-Asian-Australian monsoon analysis and prediction; Bull. Am. Meteor. Soc. 90 459-480.
Prabhakar C, Dalu G and Kunde V G 1974 Estimation of sea surface temperature from remote sensing in 11-13 $\mu \mathrm{m}$ window region; J. Geophys. Res. 79 5039-5044.

Randel D L, Vonder Haar T H, Ringerud M A, Stephens G L, Greenwald T J and Combs C L 1996 A new global water vapor dataset; Bull. Am. Meteor. Soc. 77 1233-1246.

Reynolds R W 1988 A real-time global sea surface temperature analysis; J. Climate $\mathbf{1}$ 75-86.

Reynolds R W and Smith T M 1994 Improved global sea surface temperature analyses using optimum interpolation; J. Climate 7 929-948.

Ricciardulli L and Wentz F J 2004 Uncertainties in sea surface temperature retrievals from space: Comparison of microwave and infrared observations from TRMM; J. Geophys. Res. 109, pp. C12013, doi: 10.1029/2003JC002247.

Robinson I A, Wells N C and Charnock H 1984 The sea surface thermal boundary layer and its relevance to the measurement sea surface temperature by airborne and spaceborne radiometers; Int. J. Remote Sens. 5 19-45.

Schluessel P, Emery W J, Grassl H and Mammen T 1990 On the bulk-skin temperature difference and its impact on satellite remote sensing of sea surface temperature; J. Geophys. Res. 95 13,341-13,356.

Scott N A and Chedin A 1981 A fast line by line method for atmospheric absorption computations: The authomatized atmospheric absorption atlas; J. Meteorol. 20 802-812.

Shenoi S C 1999 On the suitability of global algorithms for the retrieval of SST from the north Indian Ocean using NOAA/AVHRR data; Int. J. Remote Sens. 20 $11-29$.

Soloviev A V and Schluessel P 1996 Evolution of cool skin and direct air-sea gas transfer coefficient during daytime; Bound.-Layer Meteor. 77 45-68.

Webster P J, Clayson C A and Curry J A 1996 Clouds, radiation, and the diurnal cycle of sea surface temperature in the tropical western Pacific; J. Climate 9 1712-1730.

Wentz F and Meissner T 1999 AMSR ocean algorithm (version 2), Remote Sensing Systems (http://www.ress.com); Algorithm Theoretical Basis Document (ATBD), Santa Rosa, CA, December 1999.

Wentz F J, Gentemann C, Smith D and Chelton D 2000 Satellite measurements of sea surface temperature through clouds; Science 288 847-850.

Zhou X, Yang X, Li Z and Tao Z 2010 Single channel physical method for retrieving sea surface temperature and its sensitivity analysis; International Conference on Multimedia Technology (ICMT), pp. 1-4, 29-31, Oct. 2010. doi: 10.1109/ICMULT.2010.5631450. 